\title{
The Malaysian Polypropylene Industry Outlook In Facing ASEAN Free Trade Area (AFTA) Deregulation
}

Ahmad Zaki Bin Hj. Ismail, International Islamic University, Malaysia Sarun Bin Selamat, International Islamic University, Malaysia Elsadig Musa Ahmed, Multimedia University, Malaysia

\begin{abstract}
The objective of this study is to focus specifically on the Malaysian polypropylene industry's performance in order to further understand the current situation. As the future of the plastics industry is becoming more competitive due to the uncertainties of the global economy, it is hoped that this study could help to assist the Malaysian polypropylene industry to understand the future potential challenges better. Another aspect of the future challenges for the industry is the lifting of the trade barrier within the ASEAN countries. By early 2003, the ASEAN Free Trade Area (AFTA) has imposed in the ASEAN regions and there will be little or no tariff at all between the ten ASEAN countries. Based on the survey's results, the Malaysian polypropylene industry is still very much dependent on the domestic market. The overall domestic market share commands about $60 \%$ of the total business. The trend to expand the export market is still in progress and in line with the overall Malaysian plastics industry. At the moment, only the large polypropylene industries are very aggressive in capturing the export market. If the current market segmentation of the overall industry is maintained, the AFTA deregulation could affect the future outlook of the industry as the alternative domestic market is not available in time in case of any penetration happens to this major market segment. As the small and medium polypropylene industries are very much dependent on the domestic market, they could be the first segment of the industry that would face the immediate effect or challenges of AFTA to the industry.
\end{abstract}

Keywords: Malaysia, Polypropylene Industry's Performance, AFTA Impact.

\section{BACKGROUND, INDUSTRY AND OBJECTIVES}

\subsection{Introduction}

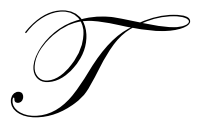

here are many industries categorized under petrochemical and one of them is the plastics industry. The Malaysian plastics industry started in early 1950 s as a cottage-industry. Through the support of the Government, and with proper industrial development plan, the Malaysian plastics industry has become one of the most important manufacturing industries in the country. As of today, the plastics manufacturing industry has become a major supporting industry of the electronics, packaging and automotive industries. In terms of contributions to the nation's economy, the plastics industry has shown a very positive growth and has good prospect for the future. In the mid 1960s, the turnover of the plastics industry was only about RM100 million. However, in 1991, it has grown tremendously to about RM1.8 billion. In the year 2000, the total turnover for the plastics industry continued to grow and was recorded at RM8.0 billion. There are few major plastics resin being consumed by the Malaysian plastics manufacturing industries such as:

- $\quad$ Polyethylene (PE);

- $\quad$ Polypropylene (PP);

- $\quad$ Polystyrene (PS); 
- $\quad$ Polyvinyl Chloride (PVC);

- $\quad$ Acrylonitrile-Butadiene-Styrene (ABS);

- $\quad$ Polyethylene Terephthalate (PET); etc.

\subsection{The Overall Polypropylene Industry}

Polypropylene plastics have consistently enjoyed a very rapid growth globally since it was commercially produced. There seems to be little indication that it has reached the demand limit. The world consumption is divided almost equally between Western Europe, Japan and America (Birley and Heath, 1982). The major global products and markets for polypropylene are Flexible and Rigid packaging (37\%), Automotive, Electrical \& Electronics and Appliances (21\%), Textile applications (18\%), and others (24\%). (Chemical Week, 2002).

Few regular reports are available for the Malaysian plastics industry which are published either by the relevant Government agencies such as Malaysian Investment Development Authority (MIDA) (MIDA, 1993) and Ministry of International Trade and Industry (MITI) (MITI 1991, 1994) or the relevant industry's associations, such as the Malaysian Plastics Manufacturers Association (MPMA) (MPMA 1998, 2002). This report is very much related and focuses on the overall performance of the overall industry and does not focus on any specific issues of the industry. In addition, there are few specific studies conducted on the Malaysian plastics industry, but the number is very limited. A study on "The Future of Plastics in Malaysia" by Dr. Tee Tiam-Ting (Tiam Ting, 1992) was published in the Malaysia Plastics Digest, Vol. xxii, No. 2, June 1992. The study specifically focused on the future outlook of the industry and concluded that it is a very potential industry for the future. Another study on "The Malaysian Plastics Manufacturing Industry - An Overview" was published by BT Information Sdn. Bhd. in the Malaysia Plastics \& Ancillary Industries bulletin in August 1993, discovered the same finding by Dr. Tee TiamTing, that the Malaysian plastics industry has a good potential growth. After about ten years of those studies, the time is right for the Malaysian plastics industry to review again the industry's future outlook. As there are lots of uncertainties on the future economic outlook, and the market becoming more competitive, the significance of this study is to provide and compliment the necessary information for the industry to review the current situation and understand the future outlook. Although this study is specifically focused on the Malaysian polypropylene industry, it is hoped that the general information would be applicable for the overall Malaysian plastics industry. This study will also provide some information on the overall status and the preparation of the Malaysian polypropylene industry in facing the AFTA challenges and trying to compete in the Association of South East Asian Nations (ASEAN) (ASEAN, 1967) markets.

\subsection{ASEAN Free Trade Area (AFTA)}

According to Chia (1980), the intra-ASEAN trade in 1978 accounted for no more than $14 \%$ of total ASEAN's global trade, amounting to US10.3 billion. The share of the member countries in the intra-ASEAN trade vary widely with Singapore at the top accounting for $47.8 \%$ of the regional trade. Seiji (1987), in his study for the intra-ASEAN trade for the period between 1969 to 1985, discovered that there was promising growth. However, the general structure of the trade within the region has not changed significantly and Singapore dominates the regional trade. In 1983, Singapore accounted approximately 50\% of total intra-ASEAN export and import. Serifah Habibah (1993), in her study on AFTA had projected that the economic impact of AFTA to be minimal. ASEAN exports in intra-ASEAN trade would increase only by about $2.9 \%$ when complete trade liberalization comes into existence. Again, according to Serifah Habibah (1993), Malaysia would enjoy the highest benefit with export increasing by $4 \%$ while Singapore's exports will only increase by $2 \%$.

Over the years the ASEAN nations have further strengthened their cooperation through various kinds of initiatives. The economic initiatives and cooperation are among the priority in the agenda and has progressed very successfully according to plan. The ultimate aim of the economic cooperation is to liberalize the ASEAN market within the ASEAN countries in preparing for the future global open market.

AFTA was then formulated by the ASEAN countries in order to achieve open market within the group by the year 2008. A permanent secretariat was formed in order to plan, monitor and provide direction for the AFTA 
implementation. As the progress of AFTA was faster than the initial plan, the target date for AFTA's implementation was then brought forward to 2003. In theory, it is expected that the trade between ASEAN countries will further expand when AFTA is fully implemented. In respect of the polypropylene industry in Malaysia, AFTA would be another potential area for the industry to grow in the future. The market for the industry are now open to much more larger population, which is estimated at slightly more than 500 million people. How the industry could exploit this potential is still subject to ASEAN's future marketing strategies and many other factors such as the global economic recovery, the ASEAN recovery after the financial crisis in 1997, political stability in the region, trade arrangement and the GDP growth of the ASEAN countries. At the same time, AFTA could also impose some negative implications to the Malaysian polypropylene industry especially those labour-intensive industry. So, now it is the right time for the Malaysian polypropylene industry to really have a strategic plan to maximize the opportunity of AFTA and to mitigate the negative implications of AFTA.

\subsection{Objectives}

The objective of this study is to focus specifically on the Malaysian polypropylene industry's performance in order to further understand the current situation. As the future of the plastics industry is becoming more competitive due to the uncertainties of the global economy, it is hoped that this study could help to assist the Malaysian polypropylene industry to understand the future potential challenges better. Another aspect of the future challenges for the industry is the lifting of the trade barrier within the ASEAN countries. By early 2003, the AFTA has been imposed in the ASEAN regions and there will be little or no tariff at all between the ten ASEAN countries. It depends very much on how much the Malaysian plastics industry is aware and understands the AFTA and its related issues, the implications to the industry can be either negative or positive for the future outlook. At the same time this study will also focus and try to understand the AFTA issue on the overall Malaysian polypropylene industry.

\section{RESEARCH DESIGN AND METHODOLOGY}

\subsection{Research Design}

The research is designed in such a manner in order to obtain as many respondents as possible within a specific time frame. There are many methods which can be applied for this research such as personal interview, telephone interview and mail survey. However, since the target groups of this study is focused on the polypropylene manufacturers all over the country, a mail survey through questionnaire method is selected as it is the most suitable and the effective way to obtain the required information from a large group of samples within the specific time frame. The research was conducted using a 7-page questionnaire, which are divided into few sections. The questionnaire was designed in a very simple and precise manner; so that the respondents would not spend too much time to answer the questions. With these concepts, the response rate is expected be better and prompt reply from the respondents would be achieved.

\subsection{Survey's Questionnaire}

Although AFTA is known by most of the Malaysian industries, however there is no proper study or survey being conducted to understand the expected impact of the changes on the new business landscape. So, the objective of the survey's questionnaires is to address and pick-up those expectations specifically for the Malaysian polypropylene industry. As this survey is very much focused to understand the new developments on the business profile in a bigger contact of ASEAN countries and the impact of AFTA to the Malaysian polypropylene industry, there is no hypothesis to be proved for this study.

To achieve the objectives of the study, the questionnaire is designed in a few sections as described in the following details:- 


\section{- $\quad$ Section 1 - Company Profile}

The objective of this section is to understand the respondents' background and the business category or profile.

\section{- $\quad$ Section 2 - Marketing}

In this section, the respondents are requested to describe their present marketing activities and future plans or strategies in marketing.

\section{- $\quad$ Section 3 - Awareness on AFTA}

The respondents are then to elaborate on their awareness and understanding on AFTA.

\section{- $\quad$ Section 4 - Expected Implication on AFTA}

This section requires further explanation from the respondents on their understanding and expected implication to their business resulting from AFTA deregulation.

\section{- $\quad$ Section 5 - Preparation for AFTA}

Finally, the questionnaire is focused on the Malaysian polypropylene industry preparation in mitigating the impact of AFTA to the industry.

\subsection{Population And Sampling}

The population understudy consisted of all the polypropylene producers or manufacturers in Malaysia, including the two eastern Malaysian states of Sabah and Sarawak. The term producers or manufacturers for this study are those organizations that are involved directly or indirectly in manufacturing of polypropylene products for domestic and export markets. Trading companies are not considered for this study as explained earlier. The producers or manufacturers could either be Malaysian-owned companies or companies owned by foreign investors but having manufacturing facilities in Malaysia. There are no specific figures and accurate statistics on the total number of the polypropylene producers in Malaysia. However, it is estimated that Malaysian polypropylene producers' population is between $35 \%-40 \%$ of the total Malaysian plastics producers and most of them are members of the Malaysian Plastics Manufactures Association (MPMA) (MPMA, 1998). As of the year 2002, it is estimated that there are about 1,300 plastics manufactures in the country and the majority of them, slightly above 900 manufacturers or $70 \%$ are registered as MPMA members. A survey on MPMA membership was conducted and it was found that 355 plastics manufacturers are involved directly or indirectly in polypropylene business. So, for the purpose of the study, the list of MPMA members is used for the survey's samples.

\subsection{Sample Size}

The initial problem to conduct the survey was to determine how large a sample should be in order to produce adequate result. However, the problem does not have a clear-cut solution since it depends upon the purpose of the study and the nature of the population under scrutiny. A sample size of 30 is held by many to be the minimum number of cases if the researcher plan to use some form of statistical analysis on the data, though techniques are available for the analysis of samples below 30 (Cohen and Manion, 1989). For the purpose of the study, a total number of 125 questionnaires were distributed to the polypropylene producers. A random sampling is utilized. However, the priority was given on those companies that are having core business on polypropylene and registered as MPMA members.

\subsection{Data Collection And Questionnaire Administration}

As mentioned earlier, the targeted respondents are located all over the country and the questionnaires were distributed through the normal postal mail. The respondents were requested to respond (by using the attached postpaid replied envelop) within a 14-day period upon receipt of the said questionnaire. Should the respondents require further clarification and explanation on the questionnaires, they could contact the sender via telephone numbers as found on the front page of the questionnaire. After about four weeks of distribution, only 31 questionnaires were received. Several follow-ups were carried out to the remaining targeted respondents and finally another 12 more questionnaires were received, making the total number of the respondents to 43 (after about 8 weeks of data collection exercise). Among the total received, 2 questionnaires were rejected as the respondents were not interested 
to answer any of the questions in the questionnaire. As a result, only 41 responses were used for the analysis of this study.

\section{FINDINGS}

\subsection{Overview Of The Findings}

This part will present the descriptive results of the overall study. The findings which are presented below are based on the views of the Top Management and the Senior Executives of the relevant companies who were involved in the survey. Based on the responses, 27 respondents came from the Top Management level while the other 14 came from the Middle Management or Senior Executive level. In general, the views and comments which were received on the same particular issues vary from the respondents' perspective. However, the common key points are considered as the general opinion for the study.

As this study is focused more on the future outlook of the Malaysian polypropylene industry; especially after AFTA deregulation, there is no specific hypotheses planned or to be proven for the study. As a result, the study is not meant for testing of any hypotheses and also there is no coverage on specific inferential statistical testing.

\subsection{Profile Of Respondents}

The majority of the respondents (63\%) are from the small and medium-sized industries (SMIs) (SMI 2002). The companies' scale or size is based on the number of full-time employees and the annual sales turnover. SMIs are characterized by companies employing not exceeding 150 full-time employees with an annual sales turnover of not exceeding RM25 million, while those companies employing more than 150 full-time employees with an annual sales turnover of more than RM25 million are categorized as large industries or companies. This profile very much reflects and matches the actual Malaysian plastics industry as the majority of the companies of this industry is categorized under the SMIs grouping.

In order to further understand the characteristics of the sample respondents, the companies were reclassified into new, established and well-established companies.

Companies established below 5 years are classified as newly established, while those companies that are more than 15 years are considered as well-established. Companies that have been in the industry between 6 to 15 years are classified as established companies. Table 1 describes the final classification of the companies.

Table 1: Respondents' Category

\begin{tabular}{|c|c|c|c|}
\hline Industry Category & $\begin{array}{c}\text { Newly Established } \\
\text { Company (Within 5years) }\end{array}$ & $\begin{array}{c}\text { Established Company } \\
\text { (6-15 years) }\end{array}$ & $\begin{array}{c}\text { Well Established } \\
\text { Company (Over 15 years) }\end{array}$ \\
Small & 0 & 3 & 6 \\
Medium & 0 & 10 & 7 \\
Large & 0 & 0 & 15 \\
Total & 0 & 13 & 28 \\
\hline
\end{tabular}

Source: Survey's Result

Based on the above data, none of the respondent belongs to the category of newly-established companies. A total of 28 respondents or $68 \%$ of them are categorized under well-established companies with more than 15 years experience in the polypropylene industry, while the other 13 respondents or 32\% are listed under established companies. So, the inputs and comments from the respondents are very much regarded as very reliable since most of them are well experienced in the industry. In terms of product segmentation, generally the respondents are involved in almost all of the polypropylene product applications. Film, injection molding and tape/yarn application sectors are the majority respondents for this study. 


\subsection{Market Segmentation}

On the overall market segmentation, an aggregate percentage data of the responds were used to formulate the understanding of the polypropylene industry's market profile. Based on the respondents' feedback, the polypropylene market profile does not differ much than the overall market of the Malaysian plastics industry. Most of the polypropylene products or about $61.3 \%$ of the total products are being consumed by the domestic market. The remaining balance of $38.7 \%$ of the total products is exported for overseas market, of which $15.7 \%$ are exported to the ASEAN countries and the remaining $23.0 \%$ are exported to the rest of the world. A detailed market profile of the polypropylene industry is shown in Table 2 .

Table 2: Polypropylene Market Profile

\begin{tabular}{|c|c|c|c|c|}
\hline Market & Industry Category & Large & Overall Average \\
& Small & Medium & $53 \%$ & $61.3 \%$ \\
Domestic & $64 \%$ & $67 \%$ & $18 \%$ & $15.7 \%$ \\
ASEAN & $13 \%$ & $16 \%$ & $29 \%$ & $23.0 \%$ \\
Rest of the World & $23 \%$ & $17 \%$ & $2 \%$ & \\
\hline
\end{tabular}

Source: Survey's Result.

From the available data, it clearly shows that the large industries are aggressively involved in the export market. Upon further analysis, it was revealed that all the large industries have a well-established networking with their overseas agents to market the export products. On the other hand, only a few well-established SMIs have overseas agents to do the same. On the future marketing strategy, only one respondent is not sure what would be the organization marketing plan for the future, whereas, four of the SMIs would maintain the focus on the domestic market as they are very competitive in the market while the remaining 36 respondents agreed to change their future marketing plans and strategies. The common reasons given were due to the potential threat from other ASEAN's polypropylene producers into the domestic market and at the same time they would like to explore the ASEAN market and expand their future business. For those companies that would like to further explore the export market, their top five priorities on the strategies are:-

1. To further improve their product quality;

2. To enhance their competitiveness in pricing;

3. To expand their volume for the economic of scale;

4. To further improve their overall business efficiencies; and

5. To expand their product range for the export market.

\subsection{Awareness On AFTA}

All the companies that participated in the survey are fully aware and confirmed that they have heard about AFTA. One hundred percent of the respondents also agree that knowing AFTA issues are very important for their current and future businesses and to some extent, a few respondents indicated that AFTA might have certain impacts on their future business. On the survey findings, it is revealed that only few companies or about $17 \%$ of them have heard about AFTA issues within the last two years, while the rest knew about the issues much earlier as shown in Table 3.

Table 3: AFTA Awareness

\begin{tabular}{|c|c|c|c|c|c|}
\hline Awareness on AFTA & \multirow{3}{|c|}{ No. of Respondents/Companies } & Total & \\
& Small & Medium & Large & & \\
Within the last 2 years & 3 & 4 & 0 & 7 & 17 \\
Within the last 5 years & 5 & 10 & 2 & 17 & 41.5 \\
More than 5 years & 1 & 3 & 13 & 17 & 41.5 \\
$\quad$ Total & 9 & 17 & 15 & 41 & 100 \\
\hline
\end{tabular}

Source: Survey's Result 
Most of the respondents from the large companies (13 out of 15), which is equivalent to $87 \%$ of them, are leading the rest in updating themselves on the AFTA issues. They have heard about the AFTA issues more than 5 years ago. This could be due to the nature of their businesses as most of the large companies or industries are involved and exposed to the export market environment as well as their long existence in the polypropylene industry.

Table 4: AFTA Overall Understanding

\begin{tabular}{|c|c|c|c|c|}
\hline Industry & Very Well & Overall Concept & Not very well & Do not understand \\
Small & 0 & 3 & 6 & 0 \\
Medium & 3 & 10 & 4 & 0 \\
Large & 4 & 11 & 0 & 0 \\
Total & 7 & 24 & 10 & 0 \\
\hline
\end{tabular}

Source: Survey's Result.

On the aspect of understanding the AFTA related issues and matters, surprisingly, very few companies or 7 out of 41 , did confirm that they fully understood on the subject matter. On the same note, all respondents understood the AFTA issues. A majority of them indicated that they understand only the overall concept of AFTA. Table 4 describes in more detail the overall understanding of the AFTA issues by the respondents.

Further studies were conducted on the AFTA understanding and it was found that $90 \%$ of the respondents required more knowledge and inputs from the relevant bodies to equip and enlighten the industry in facing the potential challenges of AFTA to their businesses.

\section{5. $\quad$ Expected Implication Of AFTA To The Polypropylene Industry}

In general, most of the respondents or 25 out of 41 agreed that there would be some impacts to their businesses due to the AFTA deregulation. However, 8 of the respondents are not really sure whether there will be any impact by the AFTA deregulation to their business, while the other 8 respondents were very confident that there would be no impact to their businesses by the AFTA deregulation. On the expected implication to the business, none of the respondent predicted that there will be any negative implication to their businesses. Sixty six percent or 27 respondents predicted that the AFTA deregulation would provide positive impacts to their business as the ASEAN market is now open to them. The potential ASEAN market is very much larger than their current domestic market since the total population of ASEAN countries is about 500 million people, compared to Malaysia's population of 23 million. In summary, Table 5 describes the detail responds of the study.

Table 5: Expected AFTA Implication on Malaysian Polypropylene Industry

\begin{tabular}{|c|c|c|c|c|c|c|c|c|c|c|}
\hline \multirow{3}{*}{$\begin{array}{c}\text { Impact To } \\
\text { business }\end{array}$} & \multicolumn{9}{|c|}{ Expected business implication } & \multirow[t]{7}{*}{ Overall } \\
\hline & & Positive & & & Negative & & & Not Sure & & \\
\hline & $\begin{array}{l}\text { Small } \\
\text { Ind. }\end{array}$ & $\begin{array}{l}\text { Medium } \\
\text { Ind. }\end{array}$ & $\begin{array}{l}\text { Large } \\
\text { Ind. }\end{array}$ & $\begin{array}{l}\text { Small } \\
\text { Ind. }\end{array}$ & $\begin{array}{l}\text { Medium } \\
\text { Ind. }\end{array}$ & $\begin{array}{l}\text { Large } \\
\text { Ind. }\end{array}$ & $\begin{array}{l}\text { Small } \\
\text { Ind. }\end{array}$ & $\begin{array}{l}\text { Medium } \\
\text { Ind. }\end{array}$ & $\begin{array}{l}\text { Large } \\
\text { Ind. }\end{array}$ & \\
\hline Yes & 6 & 8 & 5 & - & - & - & - & 4 & 2 & \\
\hline No & - & - & 8 & - & - & _ & - & - & - & \\
\hline Not Sure & - & - & - & - & - & - & 3 & 5 & - & \\
\hline Total & & 27 & & & 0 & & & 14 & & \\
\hline
\end{tabular}

Source: Survey's Result

On the positive expectation or implication of the AFTA deregulation to the Malaysian polypropylene industry, the top four comments that were received from the respondents on the potential benefits that they could gain are as follows:- 
i. $\quad$ Opportunity to expand their market share to ASEAN countries;

ii. $\quad$ Lower polypropylene resin cost as ASEAN supply exceeds the demand;

iii. Better choice and better polypropylene resin quality; and

iv. Better service and support from polypropylene resin supplier.

On the other hand, it could not be denied that there are also potential negative implications of the AFTA to the industry. General comments that were received from the respondents on the most potential negative implications of the AFTA to the Malaysian polypropylene industry are:

- Diminishing profit margin;

- Increase on the overall competitiveness;

- $\quad$ Reduce the domestic market share; and

- $\quad$ Better product range from ASEAN's competitors.

Although sixty six percent or 27 respondents initially predicted that the AFTA deregulation could offer positive impacts to their business, however, upon detailed clarification and review on both positive and negative implications, only fifty seven percent or 17 respondents, mainly from large companies, remain very confident that they could further expand or grow in the future business after AFTA is implemented.

\subsection{Preparation On AFTA Deregulation}

Although all the respondents confirmed that they have heard about the AFTA deregulation and do understand that there could be some implications to their polypropylene businesses, but based on the survey findings, not all of them have planned or has taken any initiative on their businesses to face the new changes on the business landscape. Surprisingly, about twenty nine percent or 12 of the respondents replied that they are not preparing or taking any measure on their businesses for the AFTA deregulation. All of these companies are categorized under SMIs. No specific reason was given as to why these companies are not planning or preparing for AFTA.

\section{No of Companies}

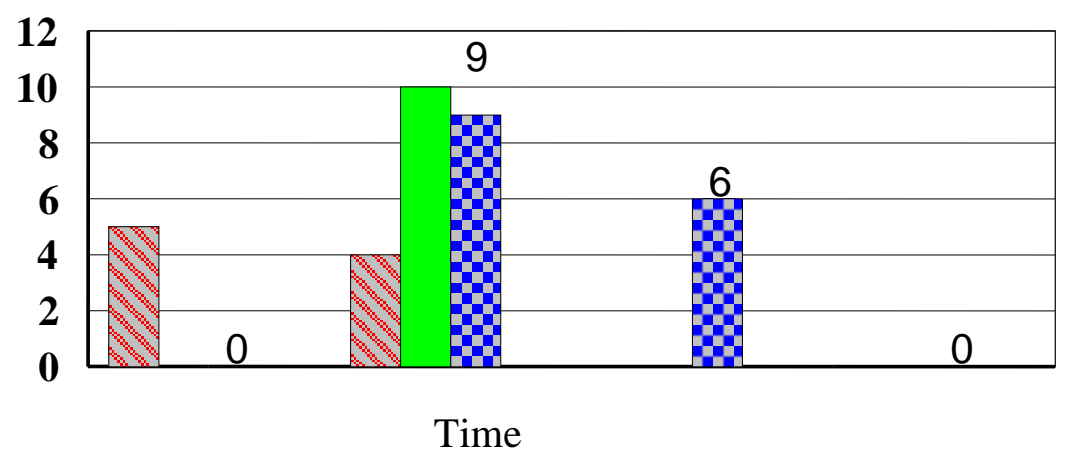

\begin{tabular}{|l|c|c|c|c|}
\hline & not prepared & The last 2 years & Between 2-5years & More than 5 years \\
\hline$\square$ Small Ind & 5 & 4 & 0 & 0 \\
\hline$\square$ Medium Ind & 7 & 10 & 0 & 0 \\
\hline Large Ind. & 0 & 9 & 6 & 0 \\
\hline$\square$ More than 5 years & 0 & 0 & 0 & 0 \\
\hline
\end{tabular}

Figure 1: Status of AFTA Preparation. Source: Survey's Result 
On the other hand, about $15 \%$ or 6 of the respondents have indicated that they have started for AFTA preparation between 2 to 5 years ago. All of these companies are categorized under large industries. The rest, 56\% of the respondents or 23 out of 41 of them have indicated that they have just started the AFTA preparation in the last 2 years. The survey also discovered that none of the respondent had started their preparation for AFTA more than 5 years ago and the detail findings is as contained in Figure 1.

Further analysis was carried out in order to understand the area of preparations by the Malaysian polypropylene industry in facing the AFTA deregulation. According to the feedback received from the respondents that are involved in the preparation, Table 6 shows the actions plan and activities focused in their strategies.

Table 6: Area of Preparations in Facing the AFTA Deregulation

\begin{tabular}{|c|l|c|}
\hline & \multicolumn{1}{|c|}{ Area of preparation/Activities } \\
I & Improve business efficiency and cost reduction & \% of respondent involved \\
II & Improve product quality & $59 \%$ \\
III & Improve manufacturing facilities & $52 \%$ \\
IV & Enhance the manpower skill & $41 \%$ \\
V & Improve the domestic market share & $41 \%$ \\
VI & Expand the overseas market share & $38 \%$ \\
VII & Organization restructuring & $31 \%$ \\
VII & Transfer the manufacturing facilities to other countries & $10 \%$ \\
\hline
\end{tabular}

Source: Survey's Result

The survey also discovered that most of the companies or the respondents, about $80 \%$ of them, are not really sure on their readiness for the AFTA. Even though some of the companies are very serious on the above activities and preparations, however, such activities and preparations only started in the last two years. As a result, their confidence level is still very low. On another aspect of the survey, $85 \%$ of the respondents indicated that they still require support and assistance from the relevant agencies, such as Government agencies, MPMA and others to support the polypropylene industry on the AFTA implementation and to mitigate the negative impacts to the industry. A few suggestions were received from the respondents such as:-

i. The relevant Government agencies shall strictly monitor the imported plastics product into the country and to impose anti-dumping law, if necessary;

ii. Malaysian Trade Corporation (MATRADE), under MITI to work closely with Malaysian plastics producers to promote and establish overseas market networking in order to penetrate the new emerging market especially from the ASEAN countries;

iii. Malaysian Plastics Manufacturers Association (MPMA) to establish a promotion fund to support the Malaysian plastics producers' activity to further expand the overseas market;

iv. To establish $R \& D$ centre for the plastic industry to meet world-class requirement; and

v. Government to explore new incentives for the industry to continue growing in the future.

\section{CONCLUSION}

Based on the survey's results, the Malaysian polypropylene industry is still very much dependent on the domestic market. The overall domestic market share commands about $60 \%$ of the total business. The trend to expand the export market is still in progress and in line with the overall Malaysian plastics industry. At the moment, only the large polypropylene industries are very aggressive in capturing the export market. If the current market segmentation of the overall industry is maintained, the AFTA deregulation could affect the future outlook of the industry as the alternative domestic market is not available in time in case of any penetration happens to this major market segment. As the small and medium polypropylene industries are very much dependent on the domestic market, they could be the first segment of the industry that would face the immediate effect or challenges of AFTA to the industry. For the large polypropylene industries, they are in a much better position in facing AFTA, as their market segmentations are quite balanced between domestic and export, of which the export market reaches about 47\%. They are more flexible in managing the business in case there is any impact of AFTA to the industry. In 
order to sustain the overall Malaysian polypropylene industry, all the involved parties in the industry and Malaysian Government agencies should seriously work together in looking into a new potential emerging market. The industry should also explore and take advantages on the positive implications of the AFTA deregulation in offering a new potential market in the region. As ASEAN is offering a huge potential market with, as indicated earlier, total population of about 500 million people, the Malaysian polypropylene industry with all the Government and nonGovernment agencies should put serious effort and strategy to capture the ASEAN market. Some of the ASEAN countries are still lacking or in the development stage in the industry and these opportunities should be optimized by the Malaysian polypropylene industry to a maximum level possible.

\section{REFERENCES}

1. ASEAN Secretariat. 18 August 1967. The ASEAN Declaration (Bangkok Declaration). Bangkok, Thailand.

2. Birley, A.W. and Heath, R.J. (1982). Plastics Material: Properties and Applications, Second Edition. Telford, UK.

3. Chemical Week. (2002). Global PP End-Markets, Application Trend.

4. Chia, S.Y. (1980). ASEAN Economic Cooperation: Proceeding of The ASEAN Economic Research Unit Workshop. Singapore.

5. Cohen, L. and Manion, L. (1989). Research Method in Education. Third Edition. Routledgr, New York.

6. MIDA Business Time. August 1993. The Malaysian Economy - Growing By Leeps and Bounds, BT Information Sdn. Bhd., Kuala Lumpur.

7. MIDA Business Time. August 1993. The Malaysian Plastics Manufacturing Industry-An Overview. BT Information Sdn. Bhd., Kuala Lumpur.

8. $\quad$ MITI Malaysia. 1991. Practical Guide to ASEAN Preferential Trade Arrangement 1984 and 1991. Kuala Lumpur.

9. $\quad$ MITI Malaysia. July 1994. Malaysia International Trade And Industry Report 1994. Berita Publishing Sdn. Bhd., Kuala Lumpur.

10. MPMA. 1998. Profile, Trend \& Future Development of the Malaysian Plastics Processing Industry. Malaysian Plastics Manufacturer Association, Petaling Jaya, Selangor.

11. MPMA. 2002. Malaysia Plastic Industry, DIRECTORY 2001/2. Malaysian Plastics Manufacturer Association, Petaling Jaya, Selangor.

12. Seiji, N. (1987). Toward an ASEAN Trade Area. Kuala Lumpur.

13. Serifah Habibah, A. M. (1993). Intra- ASEAN Trade: A Review of Malaysian Performance. Thesis for Master Program. Universiti Islam Antabangsa (UIA), Gombak, Kuala Lumpur.

14. SMI Business Directory. June 2002. Profiles \& Listing of SMIs in Malaysia. Integrated Information (M) Sdn. Bhd., Kuala Lumpur.

15. Tiam-Ting, Tee. (1992). The Future of Plastics in Malaysia. Malaysian Plastics Digest, Vol XXII, No. 2. June 1992. Kuala Lumpur. 